\title{
Effects of aspirin resistance and mean platelet volume on vascular access failure in hemodialysis patients
}

\author{
AJin Cho*, Myung Jin Choi ${ }^{*}$, Young-Ki Lee, Han Chae Hoon, Ja-Ryong Koo, Jong-Woo Yoon, and \\ Jung-Woo Noh
}

\begin{abstract}
Division of Nephrology, Department of Internal Medicine, Hallym University College of Medicine and Hallym University Kidney Research Institute, Hallym University Medical Center, Seoul, Korea
\end{abstract}

Received: March 21, 2018

Revised : April 25, 2018

Accepted: May 5, 2018

\section{Correspondence to} Jung-Woo Noh, M.D.

Division of Nephrology,

Department of Internal

Medicine, Hallym University

Kangnam Sacred Heart Hospital,

1 Singil-ro, Yeongdeungpo-gu,

Seoul 07441, Korea

Tel: +82-2-829-5108

Fax: +82-2-829-5309

E-mail:jwn8671@unitel.co.kr

\section{Jong-Woo Yoon, M.D.}

Division of Nephrology,

Department of Internal

Medicine, Hallym University

Chuncheon Sacred Heart

Hospital, 77 Sakju-ro, Chuncheon

24253, Korea

Tel: +82-33-240-5900

Fax: +82-33-255-6244

E-mail:yoonjw@hallym.or.kr

*'These authors contributed equally to this work.

Background/Aims: Maintaining the patency of vascular access (VA) in hemodialysis (HD) patients is important and can be life-saving. We investigated the effects of aspirin resistance and mean platelet volume (MPV) on VA failure in HD patients.

Methods: We enrolled 163 patients on maintenance HD. VA failure was defined as thrombosis or a decrease of $>50 \%$ of the normal vessel diameter, as revealed by angiography.

Results: Aspirin resistance was observed in 17 of 109 patients in whom this parameter was measured, and was not significantly associated with VA failure $(p=$ $0.051)$. The mean MPV was $9.15 \pm 0.05 \mathrm{fL}$. The 163 patients were grouped by the median MPV value (9.08 fL) at baseline; patients with higher MPVs $(\mathrm{n}=82)$ had lower platelet counts $(p=0.002)$ and albumin levels $(p=0.009)$. During 34 months of follow-up, 65 VA failures (39.9\%) occurred. The Kaplan-Meier curve revealed significant differences between the two groups in terms of cumulative VA failure (54.1\% vs. $35.3 \%, p=0.018$ ). On multivariate analysis, the MPV (hazard ratio [HR], 1.794; 95\% confidence interval [CI], 1.066 to 3.020; $p=0.028$ ), platelet count (HR, 1.003; 95\% CI, 1.001 to 1.006; $p=0.01$ ), and smoking status (HR, 1.894; 95\% CI, 1.019 to $3.519 ; p=0.043$ ) independently predicted VA failure.

Conclusions: A high MPV was associated with an increased risk of VA failure, whereas aspirin resistance showed only a weak association. The MPV may predict VA survival in HD patients.

Keywords: Mean platelet volume; Aspirin resistance; Renal dialysis; Vascular access

\section{INTRODUCTION}

Vascular access (VA) failure is a major problem in dialy- sis patients and maintenance of vascular patency can be life-saving. Recently, both the costs of, and morbidity associated with, management of VA failure in hemodi- 
alysis (HD) patients has increased [1]. The main cause of VA failure is outflow venous stenosis caused by vascular intimal hyperplasia and thrombosis, in turn triggered by platelet activation, endothelial cell injury, and vascular smooth muscle cell proliferation $[2,3]$. Antiplatelet therapy has been suggested to prevent VA failure [4]. However, the effectiveness of aspirin remains controversial [5-7]. Aspirin resistance is a well-known feature of patients with chronic renal failure, especially those requiring dialysis [8]. Thus, aspirin ineffectiveness may reflect aspirin resistance.

The mean platelet volume (MPV) is a known marker of atherosclerotic disease, as revealed in several epidemiological studies [9-12]. The MPV is an independent risk factor for myocardial infarction [13]. Atherosclerosis and coronary heart disease are very common in patients with end-stage renal disease (ESRD) [14,15]. Therefore, the MPV may be associated with cardiovascular disease in HD patients; in such patients, the MPV may be more affected by changes in extracellular fluid volume and composition than is the case in the general population. A relationship between the MPV and platelet aggregability may explain the association of MPV with coronary heart disease $[16,17]$. Previous studies showed that large platelets were more reactive than small platelets [18]; thus, a high MPV may be associated with VA failure. However, few studies on the effect of MPV on VA patency in HD patients have appeared. We thus investigated the effects of aspirin resistance (where aspirin serves as an antiplatelet agent) and the MVP (an indicator of platelet activation) on VA failure in HD patients.

\section{METHODS}

\section{Study population}

A total of 163 patients, with ESRD undergoing HD at Chuncheon and Kangnam Sacred Heart Hospital during January 2011, were included. All patients were $\geq$ 18 years of age, and had undergone HD two or three times weekly for $>3$ months via an arteriovenous fistula (AVF) or arteriovenous graft (AVG). The exclusion criteria were: active bleeding or bleeding requiring transfusion within the prior 4 weeks, disseminated intravascular coagulation, any cardiovascular or cerebrovascular event within the past 4 weeks, any critical illness requir- ing an intensive care unit stay, and the use of permanent or temporary HD catheters. The study complied with all relevant tenets of the Declaration of Helsinki and was approved by our Institutional Ethics Committee (Institutional Review Board, IRB approval no. 200910-74). Written informed consent was obtained from all patients.

\section{Data collection}

We recorded age, sex, body mass index, smoking status, duration of dialysis, comorbidities, any previous history of cardiovascular disease and/or VA failure, and current medication use, including antiplatelet agents. We collected dialysis records and the following biochemical data: complete blood cell count; blood urea nitrogen level; and the levels of serum creatinine, albumin, calcium, phosphorus, uric acid, intact parathyroid hormone, calcidiol, lipids, hemoglobin A1c, and C-reactive protein. Predialysis arterial blood samples were also obtained. Complete blood cell counts were measured using an ADVIA 2120 instrument (Bayer Health Care Diagnostic, Tarrytown, NY, USA). To evaluate aspirin resistance, antiplatelet effects were assessed using a VerifyNow device (Accumetrics, San Diego, CA, USA). Aspirin resistance was defined as an aspirin resistance unit (ARU) score $>550$. VA failure was defined as thrombosis or a decrease $>50 \%$ in the normal vessel diameter and $\geq 50 \%$ in the luminal diameter on angiography, accompanied by abnormal clinical findings.

\section{Statistics}

Continuous variables are presented as means with standard deviations and categorical variables as numbers with percentages. Continuous variables were compared using the independent samples $t$ test or the Wilcoxon rank-sum test. Categorical variables were compared using the Pearson chi-square test. Survival curves were plotted using the Kaplan-Meier method. Univariate and multivariate Cox's proportional hazard models were employed to determine the relationships between clinical and biochemical variables, and VA failure. All calculations were performed using SPSS software version 18.0 (SPSS Inc., Chicago, IL, USA) and a $p<0.05$ was considered significant. 


\section{RESULTS}

\section{Baseline characteristics}

The 163 subjects were divided into two groups by the median MPV (9.08 fL). Demographic, clinical, and biochemical characteristics are listed in Table 1 . The mean patient age was $57.6 \pm 12.0$ years and $79(48.5 \%)$ were male; 87 (53.4\%) had diabetes mellitus and the mean dialysis duration was $50.1 \pm 52.1$ months. Higher MPVs were more common in males with lower platelet counts (PCs). Lower albumin, total cholesterol, and low density lipoprotein cholesterol levels were seen in those with higher versus lower MPVs. The MPV/platelet ratio was higher in the higher MPV group ( $4.6 \pm 1.5$ vs. $6.7 \pm 3.2, p$ $<0.001$ ).

Aspirin resistance was observed in 17 of 109 patients (15.6\%) for whom these data were available. We divided all patients into two groups by aspirin resistance status (Table 2); the groups did not differ significantly in demographic characteristics.

\section{Clinical outcomes}

Ove a follow-up period of 34 months, 65 VA failures occurred, of which 41 were in aspirin-resistant patients. Fig. 1 shows the Kaplan-Meier curves for VA failures by aspirin-resistance status. The two groups did not differ significantly in terms of the cumulative VA failure rate ( $57 \%$ vs. $38.2 \%$, log-rank test, $p=0.051$ ). Fig. 2 shows Kaplan-Meier curves for VA failure by MPV status. A high MPV was associated with a high cumulative VA failure rate $(54.1 \%$ vs. $35.3 \%, p=0.018)$.

Cox's proportional hazard models were used to define factors predictive of VA failure (Table 3). On univariate analysis, the serum albumin level (hazard ratio [HR], o.470; 95\% confidence interval [CI], 0.260 to 0.851 ; $p=0.013)$ and the MPV (HR, 1.800; 95\% CI, 1.092 to $2.969 ; p=0.021)$ were significantly associated with VA failure. PC (HR, 1.003; 95\% CI, 1.001 to $1.006 ; p=0.069$ ) and smoking status (HR, 1.836; 95\% CI, 0.903 to 3.380; $p$ $=0.051)$ were weakly and non-significantly associated. The use of antiplatelet agents was not significantly associated with failure (HR, 1.441; 95\% CI, 0.658 to 3.158; $p$ $=0.361$ ). Aspirin resistance (measured in only 109 patients) was weakly associated with VA failure (HR, 2.043; $95 \% \mathrm{CI}, 0.973$ to $4.291 ; p=0.059)$. On multivariate analysis, the MPV (HR, 1.794; 95\% CI, 1.066 to $3.020 ; p=$
0.028), PC (HR, 1.003; 95\% CI, 1.001 to $1.006 ; p=0.01$ ), and smoking (HR, 1.894; 95\% CI, 1.019 to $3.519 ; p=0.043$ ) independently predicted VA failure. When the data were re-analyzed by access type, MVP was not associated with VA failure in the AVG group (HR, 2.245; 95\% CI, 0.689 to $7.312 ; p=0.180$ ). However, this group contained only 22 patients.

\section{DISCUSSION}

VA is essential for HD patients. Vascular intimal hyperplasia and thrombosis are the main causes of VA failure, triggered by platelet activation, endothelial cell injury, and vascular smooth muscle cell proliferation [1921]. Low-dose aspirin did not maintain AVF patency or prevent AVF failure in a previous study [22,23]. Aspirin resistance is a well-known cause of treatment failure in patients with peripheral vascular and cardiovascular disease [24-26]. Li et al. [27] found that aspirin resistance was associated with a 2.4-fold greater risk of major adverse cardiovascular events in patients with coronary heart disease who complied well with aspirin therapy. Kim et al. [28] reported increased aspirin resistance (20\%) in Korean ESRD patients on both HD and peritoneal dialysis. Although the relationship between aspirin resistance and VA failure was not examined, the incidence of thrombotic cardiovascular complications was much higher in nine of 12 (75\%) aspirin-resistant patients than in 18 of $47(38 \%)$ aspirin-sensitive patients [28]; thus, aspirin resistance may explain failure of AVF patency. In this study, $15.6 \%$ of patients exhibited aspirin resistance that was only weakly associated with VA failure. This is the first report to explore this relationship and more work is needed.

The MPV is associated with cardiovascular disease risk. Sansanayudh et al. [29] reported that an increased MPV was an independent risk factor in patients with coronary heart disease. Varol and Ozaydin [30] reported that the MPV was elevated in patients with chronic renal failure. Henning et al. [31] found that the MPV was associated with coronary heart disease in HD patients. We found that the MPV independently predicted VA failure in HD patients (on both low-dose or no aspirin); as aspirin does not affect the MPV, it would have had no impact on this result [32]. We also found that a high 
Cho A, et al. Mean platelet volume and vascular access failure

Table 1. Baseline characteristics according to mean platelet volume

\begin{tabular}{|c|c|c|c|}
\hline Characteristic & $\operatorname{MPV}(<9.08 \mathrm{fL})(\mathrm{n}=81)$ & $\operatorname{MPV}(\geq 9.08 \mathrm{fL})(\mathrm{n}=82)$ & $p$ value \\
\hline Age, yr & $56.5 \pm 11.8$ & $58.6 \pm 12.1$ & 0.257 \\
\hline Male sex & $33(40.7)$ & $46(56.1)$ & 0.049 \\
\hline $\mathrm{BMI}, \mathrm{kg} / \mathrm{m}^{2}$ & $22.3 \pm 3 \cdot 5$ & $22 \pm 3.2$ & 0.765 \\
\hline Diabetes mellitus & $43(53.1)$ & $44(53.7)$ & 0.942 \\
\hline Predialysis SBP, mmHg & $147.5 \pm 16.3$ & $151 \pm 17.6$ & 0.192 \\
\hline Predialysis DBP, mmHg & $83 \pm 7 \cdot 7$ & $83.4 \pm 10.2$ & 0.919 \\
\hline Coronary heart disease & $25(30.9)$ & $24(29 \cdot 3)$ & 0.824 \\
\hline Cerebral vascular disease & $17(21.3)$ & $23(28.1)$ & 0.315 \\
\hline Previous vascular failure & $25(30.9)$ & $35(42.7)$ & 0.118 \\
\hline Hemodialysis vintage, mon & $46.4 \pm 48.3$ & $53 \cdot 7 \pm 55 \cdot 6$ & 0.593 \\
\hline $\mathrm{UFR}, \mathrm{mL} / \mathrm{min}$ & $2.5 \pm 0.9$ & $2.7 \pm 1.0$ & 0.216 \\
\hline Smoking & $10(12.4)$ & $14(17.1)$ & 0.394 \\
\hline $\mathrm{WBC}, \times 10^{3} / \mu \mathrm{L}$ & $6.4 \pm 1.7$ & $6.1 \pm 2.0$ & 0.130 \\
\hline Hemoglobin, g/dL & $10.3 \pm 0.7$ & $10.2 \pm 0.9$ & 0.366 \\
\hline Hematocrit, \% & $31.3 \pm 2.1$ & $31 \pm 3.0$ & 0.572 \\
\hline Platelet, $\times 10^{3} / \mu \mathrm{L}$ & $204 \cdot 4 \pm 59 \cdot 7$ & $171.2 \pm 76.8$ & 0.002 \\
\hline Calcium, mg/dL & $8.3 \pm 0.8$ & $8.2 \pm 0.7$ & 0.316 \\
\hline Phsphorus, mg/dL & $4.9 \pm 1.0$ & $4.8 \pm 1.2$ & 0.507 \\
\hline $\mathrm{Ca} \times \mathrm{P}$ product, $\mathrm{mg}^{2} / \mathrm{dL}^{2}$ & $41.1 \pm 10.3$ & $39.7 \pm 11.4$ & 0.455 \\
\hline${ }_{25}(\mathrm{OH})$ vitamin $\mathrm{D}, \mathrm{ng} / \mathrm{mL}$ & $11.4 \pm 7.6$ & $11.2 \pm 5.8$ & 0.494 \\
\hline Intact PTH, pg/mL & $223 \cdot 3 \pm 168.4$ & $211.4 \pm 195.6$ & 0.355 \\
\hline Uric acid, mg/dL & $6.4 \pm 1.1$ & $6.3 \pm 1.2$ & 0.297 \\
\hline BUN, mg/dL & $43.8 \pm 11.7$ & $46.5 \pm 14.2$ & 0.372 \\
\hline Creatinine, mg/dL & $6.6 \pm 2.0$ & $6.9 \pm 2.0$ & 0.299 \\
\hline Protein, g/dL & $6.6 \pm 0.5$ & $6.4 \pm 0.7$ & 0.093 \\
\hline Albumin, g/dL & $3.9 \pm 0.3$ & $3.8 \pm 0.4$ & 0.009 \\
\hline Total cholesterol, mg/dL & $148 \pm 27.8$ & $133.5 \pm 30.0$ & 0.002 \\
\hline Triglyceride, mg/dL & $127.6 \pm 90.0$ & $115.6 \pm 99.2$ & 0.084 \\
\hline $\mathrm{HDL}-\mathrm{C}, \mathrm{mg} / \mathrm{dL}$ & $39.7 \pm 10.4$ & $40 \pm 11.6$ & 0.825 \\
\hline $\mathrm{LDL}-\mathrm{C}, \mathrm{mg} / \mathrm{dL}$ & $81.1 \pm 24$ & $71.8 \pm 21.7$ & 0.010 \\
\hline Hemoglobin Aic, \% & $7.0 \pm 1.5$ & $7.1 \pm 1.3$ & 0.490 \\
\hline $\mathrm{CRP}, \mathrm{mg} / \mathrm{L}$ & $20.6 \pm 27.1$ & $20.8 \pm 30.5$ & 0.786 \\
\hline MPV/platelet ratio $(\mathrm{MPV} \times 100 / \mathrm{PC})$ & $4.6 \pm 1.5$ & $6.7 \pm 3.2$ & $<0.001$ \\
\hline Aspirin & $70(86.4)$ & $62(75.6)$ & 0.079 \\
\hline Clopidogrel & $10(12 \cdot 3)$ & $9(11)$ & 0.785 \\
\hline Cilostazol & $6(7 \cdot 4)$ & $7(8.5)$ & 0.790 \\
\hline Warfarin & $1(1.2)$ & 0 & 0.313 \\
\hline
\end{tabular}

Values are presented as mean \pm SD or number (\%).

MPV, mean platelet volume; BMI, body mass index; SBP, systolic blood pressure; DBP, diastolic blood pressure; UFR, ultrafiltration rate; WBC, white blood cell; Ca, calcium; P, phosphorus; $25(\mathrm{OH})$ vitamin $\mathrm{D}$, calcidiol; PTH, parathyroid hormone; BUN, blood urea nitrogen; HDL-C, high density lipoprotein cholesterol; LDL-C, low density lipoprotein cholesterol; CRP, C-reactive protein; PC, platelet count. 
Table 2. Baseline characteristics according to aspirin resistance

\begin{tabular}{|c|c|c|c|}
\hline Characteristic & Aspirin resistance $(\mathrm{n}=17)$ & Aspirin sensitive $(n=92)$ & $p$ value \\
\hline Age, yr & $59 \cdot 3 \pm 13.1$ & $57.1 \pm 12.1$ & 0.523 \\
\hline Male sex & $9(52.9)$ & $40(43.5)$ & 0.472 \\
\hline $\mathrm{BMI}, \mathrm{kg} / \mathrm{m}^{2}$ & $22.3 \pm 3.3$ & $22.3 \pm 3.7$ & 0.976 \\
\hline Diabetes mellitus & $10(58.8)$ & $37(40.2)$ & 0.157 \\
\hline Predialysis SBP, mmHg & $148.8 \pm 15 \cdot 3$ & $151.5 \pm 17.5$ & 0.524 \\
\hline Predialysis DBP, mmHg & $82.8 \pm 7.2$ & $84.1 \pm 10.2$ & 0.539 \\
\hline Coronary heart disease & $5(29.4)$ & $30(32.6)$ & 0.794 \\
\hline Cerebral vascular disease & $3(23.5)$ & $20(21.7)$ & 0.871 \\
\hline Previous vascular failure & $5(29 \cdot 4)$ & $33(35 \cdot 9)$ & 0.608 \\
\hline Hemodialysis vintage, mon & $54 \cdot 4 \pm 55 \cdot 5$ & $47.7 \pm 50.0$ & 0.647 \\
\hline $\mathrm{UFR}, \mathrm{mL} / \mathrm{min}$ & $2.7 \pm 1.1$ & $2.7 \pm 1.0$ & 0.980 \\
\hline Smoking & $4(23 \cdot 5)$ & $11(12.0)$ & 0.232 \\
\hline $\mathrm{WBC}, \times 10^{3} / \mu \mathrm{L}$ & $6.2 \pm 1.9$ & $6.4 \pm 1.9$ & 0.673 \\
\hline Hemoglobin, g/dL & $10.3 \pm 0.9$ & $10.3 \pm 0.8$ & 0.891 \\
\hline Hematocrit, \% & $31.0 \pm 2.8$ & $31.1 \pm 2.6$ & 0.893 \\
\hline Platelet, $\times 10^{3} / \mu \mathrm{L}$ & $204.4 \pm 59 \cdot 7$ & $171.2 \pm 76.8$ & 0.332 \\
\hline Calcium, mg/dL & $8.0 \pm 0.8$ & $8.3 \pm 0.8$ & 0.141 \\
\hline Phsphorus, mg/dL & $4.6 \pm 0.8$ & $4.9 \pm 1.1$ & 0.160 \\
\hline $\mathrm{Ca} \times \mathrm{P}$ product, $\mathrm{mg}^{2} / \mathrm{dL}^{2}$ & $37.1 \pm 7.8$ & $41.5 \pm 11.9$ & 0.060 \\
\hline${ }_{25}(\mathrm{OH})$ vitamin $\mathrm{D}, \mathrm{ng} / \mathrm{mL}$ & $12.2 \pm 6.2$ & $10.3 \pm 6.5$ & 0.262 \\
\hline Intact PTH, pg/mL & $154.0 \pm 122.4$ & $204 \cdot 5 \pm 184 \cdot 7$ & 0.163 \\
\hline Uric acid, mg/dL & $6.8 \pm 1.5$ & $6.3 \pm 1.1$ & 0.188 \\
\hline BUN, mg/dL & $43.2 \pm 13.8$ & $45.2 \pm 13.8$ & 0.578 \\
\hline Creatinine, mg/dL & $6.1 \pm 2.0$ & $6.7 \pm 2.0$ & 0.333 \\
\hline Protein, g/dL & $6.4 \pm 0.5$ & $6.5 \pm 0.7$ & 0.435 \\
\hline Albumin, g/dL & $3.9 \pm 0.3$ & $3.8 \pm 0.4$ & 0.860 \\
\hline Total cholesterol, mg/dL & $143.0 \pm 41.2$ & $144 \cdot 3 \pm 28.9$ & 0.898 \\
\hline Triglyceride, mg/dL & $132.4 \pm 79.1$ & $123.2 \pm 88.9$ & 0.670 \\
\hline $\mathrm{HDL}-\mathrm{C}, \mathrm{mg} / \mathrm{dL}$ & $42.2 \pm 9.1$ & $39.1 \pm 11.4$ & 0.227 \\
\hline $\mathrm{LDL}-\mathrm{C}, \mathrm{mg} / \mathrm{dL}$ & $81.1 \pm 25.8$ & $77.9 \pm 22.4$ & 0.633 \\
\hline Hemoglobin Aıc, \% & $6.8 \pm 1.1$ & $7.2 \pm 1.5$ & 0.326 \\
\hline $\mathrm{CRP}, \mathrm{mg} / \mathrm{L}$ & $46.5 \pm 47.6$ & $18.4 \pm 25.8$ & 0.202 \\
\hline
\end{tabular}

Values are presented as mean \pm SD or number (\%).

BMI, body mass index; SBP, systolic blood pressure; DBP, diastolic blood pressure; UFR, ultrafiltration rate; WBC, white blood cell; Ca, calcium; P, phosphorus; $25(\mathrm{OH})$ vitamin D, calcidiol; PTH, parathyroid hormone; BUN, blood urea nitrogen; HDL-C, high density lipoprotein cholesterol; LDL-C, low density lipoprotein cholesterol; CRP, C-reactive protein.

PC was associated with VA failure. An earlier epidemiological study reported that a high PC was associated with cardiovascular disease [33]. We found that the high-MPV group had a lower PC than the low-MPV group, reflect- ing the inverse relationship between MPV and platelet number [34]. Smoking was independently associated with VA failure, as also found in previous studies [35,36].

MPV reduction may prevent VA failure and stenosis. 


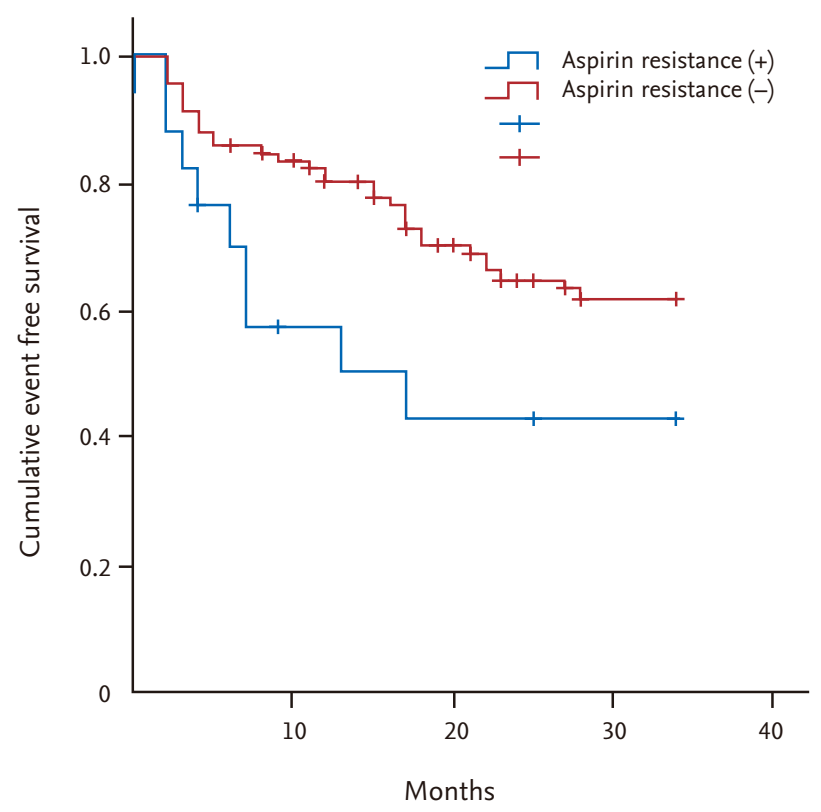

Figure 1. Kaplan-Meier curves for vascular access failure according to aspirin resistance $(p=0.051)$.

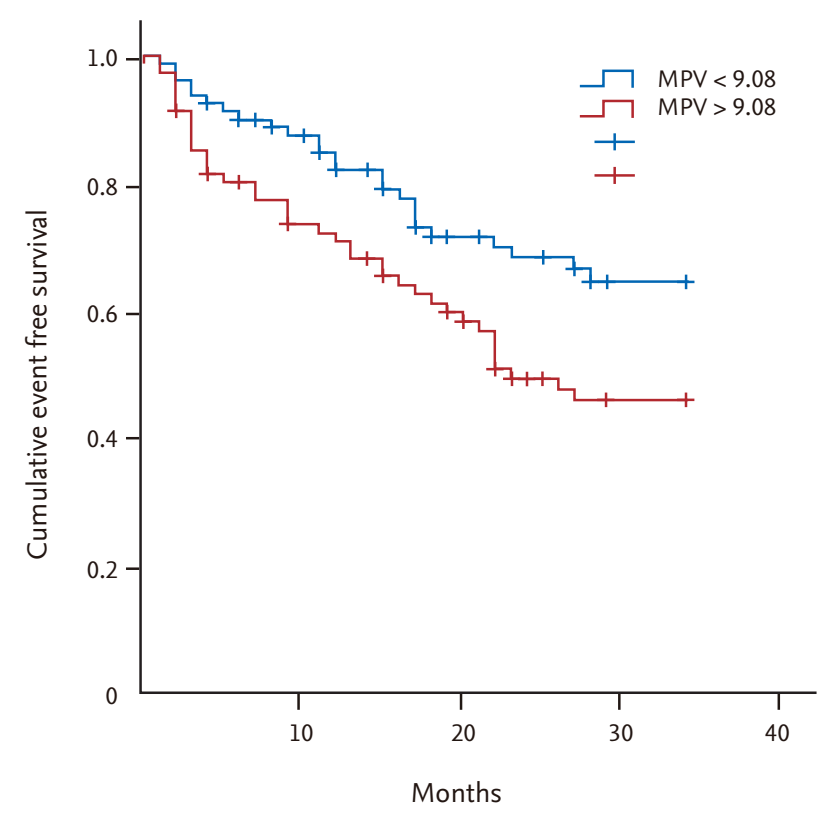

Figure 2. Kaplan-Meier curves for vascular access failure according to mean platelet volume $(\mathrm{MPV})(p=0.018)$.

Table 3. Univariate and multivariate cox proportional hazard models for vascular access failure

\begin{tabular}{|c|c|c|c|c|c|c|}
\hline \multirow{2}{*}{ Variable } & \multicolumn{3}{|c|}{ Univariate analysis } & \multicolumn{3}{|c|}{ Multivariate analysis } \\
\hline & HR & $95 \% \mathrm{CI}$ & $p$ value & HR & $95 \%$ CI & $p$ value \\
\hline Age, /yr & 1.005 & $0.984-1.026$ & 0.651 & & & \\
\hline Male (vs. female) & 1.470 & $0.901-2.399$ & 0.123 & & & \\
\hline $\mathrm{BMI}, / \mathrm{kg} / \mathrm{m}^{2}$ & 1.018 & $0.945^{-1.097}$ & 0.630 & & & \\
\hline DM (vs. no) & 1.489 & $0.903-2.455$ & 0.119 & & & \\
\hline Smoker (vs. no) & 1.836 & $0.997-3.380$ & 0.051 & 1.894 & $1.019-3.519$ & 0.043 \\
\hline Platelet, $/ 10^{3} / \mu \mathrm{L}$ & 1.003 & $1.000-1.006$ & 0.069 & 1.003 & $1.001-1.006$ & 0.010 \\
\hline Albumin, /g/dL & 0.470 & $0.260-0.851$ & 0.013 & 0.582 & $0.310-1.094$ & 0.093 \\
\hline Cholesterol, /mg/dL & 0.998 & $0.990-1.006$ & 0.629 & & & \\
\hline $\mathrm{LDL}-\mathrm{C}, / \mathrm{mg} / \mathrm{dL}$ & 1.000 & $0.989-1.010$ & 0.954 & & & \\
\hline Previous VA failure (vs. no) & 1.368 & $0.835^{-2.242}$ & 0.214 & & & \\
\hline Aspirin resistance (vs. no) & 2.043 & $0.973-4.291$ & 0.059 & & & \\
\hline Antiplatelet agent (vs. no) & 1.441 & $0.658-3.158$ & 0.361 & & & \\
\hline $\operatorname{MPV}($ vs. $<9.08 \mathrm{fL})$ & 1.800 & $1.092-2.969$ & 0.021 & 1.794 & $1.066-3.020$ & 0.028 \\
\hline MPV/platelet ratio & 0.945 & $0.853-1.048$ & 0.285 & & & \\
\hline
\end{tabular}

HR, hazard ratio; CI, confidence interval; BMI, body mass index; DM, diabetes mellitus; LDL-C, low density lipoprotein cholesterol; VA, vascular access; MPV, mean platelet volume.

${ }^{\mathrm{a}} 109$ patients were included.

Yazici et al. [37] reported that lifestyle modifications reduced the MPV in pre-hypertensive patients. As the MPV is affected by low-dose aspirin, such treatment does not reduce the MPV, in line with the findings that aspirin did not maintain AVF patency or prevent AVF failure. Lee et al. [38] found that statin/ezetimibe combi- 
nation therapy reduced the MPV more so than did statin monotherapy alone. A high MVP was associated with diabetes, especially the HbArc level, and strict blood sugar control reduced the MVP [37-39]. Both the MPV per se and the MPV/platelet ratio were associated with cardiovascular disease [40]. Recently. Shin et al. [41] found that an increase in the MPV/platelet ratio over 3 months was associated with VA failure in HD patients. As the MPV and platelet numbers are inversely related, a higher MPV/platelet ratio should independently predict VA failure. Indeed, the MPV/platelet ratio was higher in the high than the low MPV group of the present study. However, the ratio did not affect the AVF patency rate in either univariate or multivariate analysis; other factors may be involved. In the cited work, the MPV and platelet were not inversely related and neither independently predicted VA failure. Further study is needed.

Our study had several limitations. First, we measured the MPV and platelet only once, before any VA event. Longitudinal variations in these parameters may affect VA failure. Second, this was a single-center study. Third, we collected blood into ethylenediaminetetraacetic acid (EDTA) tubes, perhaps associated with platelet swelling. However, all analyses were performed within $30 \mathrm{~min}$ utes of sampling to minimize laboratory errors.

In conclusion, we found that an increase in the MPV independently predicted VA failure in HD patients. Aspirin resistance was only weakly associated with VA failure. MPV reduction might help prevent VA failure; further study is needed to validate this.

\section{KEY MESSAGE}

1. High mean platelet volume (MPV) was an independent risk factor for vascular access failure in hemodialysis patients.

2. Aspirin resistance showed a weak relationship with vascular access failure

3. High MVP is regarded as a potential marker for prediction of vascular access survival in hemodialysis patients.

\section{Conflict of interest}

No potential conflict of interest relevant to this article was reported.

\section{Acknowledgments}

This work was supported by a grant from Hallym University Medical Center Research fund (01-2009-12).

\section{REFERENCES}

1. Hakim R, Himmelfarb J. Hemodialysis access failure: a call to action. Kidney Int 1998;54:1029-1040.

2. Stracke S, Konner K, Kostlin I, et al. Increased expression of TGF-betaı and IGF-I in inflammatory stenotic lesions of hemodialysis fistulas. Kidney Int 2002;61:1011-1019.

3. Sterpetti AV, Cucina A, Santoro L, Cardillo B, Cavallaro A. Modulation of arterial smooth muscle cell growth by haemodynamic forces. Eur J Vasc Surg 1992;6:16-20.

4. Himmelfarb J. Pharmacologic prevention of vascular access stenosis. Curr Opin Nephrol Hypertens 1999;8:569572.

5. Sreedhara R, Himmelfarb J, Lazarus JM, Hakim RM. Anti-platelet therapy in graft thrombosis: results of a prospective, randomized, double-blind study. Kidney Int 1994;45:1477-1483.

6. Kaufman JS, O'Connor TZ, Zhang JH, et al. Randomized controlled trial of clopidogrel plus aspirin to prevent hemodialysis access graft thrombosis. J Am Soc Nephrol 2003;14:2313-2321.

7. Saran R, Dykstra DM, Wolfe RA, et al. Association between vascular access failure and the use of specific drugs: the Dialysis Outcomes and Practice Patterns Study (DOPPS). Am J Kidney Dis 2002;40:1255-1263.

8. Kilickesmez KO, Kocas C, Abaci O, Okcun B, Gorcin B, Gurmen T. Follow-up of aspirin-resistant patients with end-stage kidney disease. Int Urol Nephrol 2013;45:10971102.

9. Bath PM, Missouris CG, Buckenham T, MacGregor GA. Increased platelet volume and platelet mass in patients with atherosclerotic renal artery stenosis. Clin Sci (Lond) 1994;87:253-257.

10. Tschope D, Langer E, Schauseil S, Rosen P, Kaufmann L, Gries FA. Increased platelet volume: sign of impaired thrombopoiesis in diabetes mellitus. Klin Wochenschr 1989;67:253-259.

11. Valkila EH, Salenius JP, Koivula TA. Platelet indices in patients with occlusive carotid artery disease. Angiology 1994;45:361-365.

12. D'Erasmo E, Aliberti G, Celi FS, Romagnoli E, Vecci E, 
Mazzuoli GF. Platelet count, mean platelet volume and their relation to prognosis in cerebral infarction. J Intern Med 1990;227:11-14.

13. Martin JF, Bath PM, Burr ML. Influence of platelet size on outcome after myocardial infarction. Lancet 1991;338:1409-1411.

14. Ibels LS, Stewart JH, Mahony JF, Neale FC, Sheil AG. Occlusive arterial disease in uraemic and haemodialysis patients and renal transplant recipients: a study of the incidence of arterial disease and of the prevalence of risk factors implicated in the pathogenesis of arteriosclerosis. Q J Med 1977;46:197-214.

15. Lindner A, Charra B, Sherrard DJ, Scribner BH. Accelerated atherosclerosis in prolonged maintenance hemodialysis. N Engl J Med 1974;290:697-701.

16. Martin JF, Plumb J, Kilbey RS, Kishk YT. Changes in volume and density of platelets in myocardial infarction. $\mathrm{Br}$ Med J (Clin Res Ed) 1983;287:456-459.

17. Jakubowski JA, Thompson CB, Vaillancourt R, Valeri CR, Deykin D. Arachidonic acid metabolism by platelets of differing size. Br J Haematol 1983;53:503-511.

18. Martin JF, Trowbridge EA, Salmon G, Plumb J. The biological significance of platelet volume: its relationship to bleeding time, platelet thromboxane B2 production and megakaryocyte nuclear DNA concentration. Thromb Res 1983;32:443-460.

19. Brahmbhatt A, Remuzzi A, Franzoni M, Misra S. The molecular mechanisms of hemodialysis vascular access failure. Kidney Int 2016;89:303-316.

20. Hasegawa T, Elder SJ, Bragg-Gresham JL, et al. Consistent aspirin use associated with improved arteriovenous fistula survival among incident hemodialysis patients in the dialysis outcomes and practice patterns study. Clin J Am Soc Nephrol 2008;3:1373-1378.

21. Jackson AJ, Coats P, Kingsmore DB. Pharmacotherapy to improve outcomes in vascular access surgery: a review of current treatment strategies. Nephrol Dial Transplant 2012;27:2005-2016.

22. Irish AB, Viecelli AK, Hawley CM, et al. Effect of fish oil supplementation and aspirin use on arteriovenous fistula failure in patients requiring hemodialysis: a randomized clinical trial. JAMA Intern Med 2017;177:184-193.

23. Murley A, Wijewardane A, Wilmink T, Baharani J. Should patients be on antithrombotic medication for their first arteriovenous fistulae? J Vasc Access 2016;17:118-123.

24. Guirgis M, Thompson P, Jansen S. Review of aspirin and clopidogrel resistance in peripheral arterial disease. J Vasc Surg 2017;66:1576-1586.

25. Pasala T, Hoo JS, Lockhart MK, et al. Aspirin resistance predicts adverse cardiovascular events in patients with symptomatic peripheral artery disease. Tex Heart Inst J 2016;43:482-487.

26. Liu L, Gao YH, Cao J, et al. High prevalence of aspirin resistance in elderly patients with cardiovascular disease and metabolic syndrome. J Geriatr Cardiol 2016;13:531536.

27. Li J, Song M, Jian Z, et al. Laboratory aspirin resistance and the risk of major adverse cardiovascular events in patients with coronary heart disease on confirmed aspirin adherence. J Atheroscler Thromb 2014;21:239-247.

28. Kim HW, Jang EH, Kim SY, Kim KS, Joo SJ. Aspirin resistance in patients with end-stage renal disease. Korean J Nephrol 2011;30:163-170.

29. Sansanayudh N, Muntham D, Yamwong S, Sritara P, Akrawichien T, Thakkinstian A. The association between mean platelet volume and cardiovascular risk factors. Eur J Intern Med 2016;30:37-42.

30. Varol E, Ozaydin M. Mean platelet volume measurement in chronic renal failure: confounding factors must have been taken into account. Ren Fail 2014;36:488.

31. Henning BF, Zidek W, Linder B, Tepel M. Mean platelet volume and coronary heart disease in hemodialysis patients. Kidney Blood Press Res 2002;25:103-108.

32. Colkesen Y, Coskun I, Muderrisoglu H. The effect of aspirin on mean platelet volume in patients with paroxysmal atrial fibrillation. Platelets 2013;24:263-266.

33. Vinholt PJ, Hvas AM, Frederiksen H, Bathum L, Jorgensen MK, Nybo M. Platelet count is associated with cardiovascular disease, cancer and mortality: a population-based cohort study. Thromb Res 2016;148:136-142.

34. Levin J, Bessman JD. The inverse relation between platelet volume and platelet number. Abnormalities in hematologic disease and evidence that platelet size does not correlate with platelet age. J Lab Clin Med 1983;101:295307.

35. Gheith OA, Kamal MM. Risk factors of vascular access failure in patients on hemodialysis. Iran J Kidney Dis 2008;2:201-207.

36. Monroy-Cuadros M, Yilmaz S, Salazar-Banuelos A, Doig C. Risk factors associated with patency loss of hemodialysis vascular access within 6 months. Clin J Am Soc Nephrol 2010;5:1787-1792. 
37. Yazici M, Kaya A, Kaya Y, Albayrak S, Cinemre H, Ozhan $\mathrm{H}$. Lifestyle modification decreases the mean platelet volume in prehypertensive patients. Platelets 2009;20:58-63.

38. Lee JB, Kim GS, Cho HN. Statin and ezetimibe combination therapy decreases mean platelet volume compared to statin monotherapy. J Stroke 2017;19:109-110.

39. Oshima S, Higuchi T, Okada S, Takahashi O. The relationship between mean platelet volume and fasting plasma glucose and hbarc levels in a large cohort of unselected health check-up participants. J Clin Med Res 2018;10:345-
350.

40. Azab B, Torbey E, Singh J, et al. Mean platelet volume/ platelet count ratio as a predictor of long-term mortality after non-ST-elevation myocardial infarction. Platelets 2011;22:557-566.

41. Shin DH, Rhee SY, Jeon HJ, Park JY, Kang SW, Oh J. An increase in mean platelet volume/platelet count ratio is associated with vascular access failure in hemodialysis patients. PLoS One 2017;12:e0170357. 